\title{
Tikrinių vardų galūnių adaptavimo ypatumai Simono Daukanto ir Simono Stanevičiaus Epitome Historiae Sacrae vertimuose
}

\author{
BIRUTĖ GUDELIENÉ \\ Lietuvių kalbos institutas, P. Vileišio g. 5, LT-10308 Vilnius \\ El.paštas birutegud@inbox.lt
}

\begin{abstract}
Straipsnis aktualus XIX a. pirmosios pusės skirtingų autorių religinio teksto vertime esančių tikrinių biblinių vardų galūnių vartosena ir adaptavimu, nes nuo seno nusistovejjusios biblinių vardų rašybos nebuvo, o Simono Daukanto ir Simono Stanevičiaus vartoti tikriniai bibliniai vardai nebuvo išsamiai analizuoti. Tyrimo duomenys galètų būti naudingi vertinant tikrinių vardų adaptacijos raidą, situaciją XIX a. pirmojoje pusèje.

Darbe stengiamasi nustatyti, koks yra kiekvieno autoriaus norminimo pobūdis, kiek jis siejasi su galūnių rašyba XIX a. ir ankstesnių metų raštuose, kokia tarmès ịtaka galūnių rašybai ir abiejų vertėjų rašybos galūnèse santykis.

Raktažodžiai: Stanevičius, Daukantas, bibliniai vardai, norminimas, galūnių rašyba
\end{abstract}

\section{IVADAS}

Darbo tikslas - ištirti biblinių asmenvardžių ir vietovardžių galūnių rašymo ir adaptavimo pobūdị iš pasirinktų religinio pobūdžio šaltinių (pateikiama toliau). Darbo uždaviniai - nustatyti, kokios yra tiriamųjų šaltinių vardų galūnės: išlaikytos sveikos - aukštaitiškos ar sutrumpejusios - žemaitiškos, kaip jas rašo kiekvienas iš autorių ir kaip jos adaptuojamos lietuviams. Dar stengiamasi palyginti skirtingų autorių pateikiamus vardus Senojo Testamento vertimuose.

Tyrimo šaltiniai - S. Stanevičiaus vertimas Historyia szwenta (1823), taip pat S. Daukanto verstos Epitome Historiae Sacrae (1838) lietuviškos antraštės ir Žodrodys, padèsiantys patikslinti dèsningumus. Papildomai remtasi S. Stanevičiaus Apey darima walge ysz kiarpu Islandu pagal datirima Teodora Branderburga (1823). Darbe pateikiama naujų duomenų apie S. Stanevičiaus ir S. Daukanto vertimo tikrinių vardų galūnių rašybą, taip pat apie S. Stanevičiaus vertimo rašmenis su diakritikais galūnèje. 
Ilgą laiką tikriniai bibliniai vardai buvo rašomi ̨̇vairiai, nesistemingai, o norminė biblinių vardų adaptacija ị lietuvių kalbą pasirodè tik 2000-aisiais. Valstybinė lietuvių kalbos komisija prie Lietuvos Respublikos Seimo, pataisiusi Lietuvos Biblijos draugijos rengiamo spaudai ekumeninio leidimo Šventojo Rašto vardyną, 19970619 posėdyje (protokolas Nr. 6) patvirtino jị ir 19970828 posėdyje prièmé nutarimą Nr. 62 „Dèl Biblijos vardų adaptavimo principuc “ $[13,60-61]$.

Adaptuojant tikrinius asmenvardžius ir vietovardžius ị lietuvių kalbą labai daug dèmesio skiriama šaknies adaptacijai. Remiantis Biblijos vertimų i šiuolaikines kalbas pasauline praktika, prie hebrajiško (ir aramejjiško) originalo kiek galima daugiau priartinami tie Senojo Testamento vardai, kurių lietuviška forma neturi senesnès vartojimo tradicijos. Kiti vardai, į lietuvių kalbą patekę ne tiesiogiai iš hebrajų kalbos, bet per graikiškus (Septuagìnta) bei lotyniškus (Vulgatà) Senojo Testamento vertimus arba per Naujaji Testamentą ir turintys nusistovejusią formą, laikytini tradiciniais. Visi kiti principai susiję su fonetikos dalykais ir adaptuojant pridedamomis lietuviškomis galūnèmis arba baigmenimis.

Remiantis tyrimo medžiaga akivaizdu, kad Daukantas ir Stanevičius adaptavo tikrinių vardų galūnes (priešingai nei norminiame Biblijos vardų žodyne, XIX a. ir anksčiau dèmesys buvo skiriamas galūnių adaptacijai), tai ir bus aptarta straipsnyje. Analizuojamos tik šiuose darbuose pateiktos originalios asmenvardžių galūnès. Iš viso rasta 302 tikrinių asmenvardžių ir vietovardžių pavyzdžiai, straipsnyje pasinaudota dalimi jų.

Bibliniai asmenvardžiai ir vietovardžiai po tildès ženklo atkuriami remiantis norminèmis formomis pagal Biblijos vardų žodyną (2000). Straipsnyje taikyti literatūros apžvalgos, aprašomasis, lyginamasis metodai.

\section{S. STANEVIČIAUS IR S. DAUKANTO GALŪNIŲ RAŠYBOS TYRIMU APŽVALGA}

S. Stanevičiaus vertimo Historyia szwenta asmenvardžių galūnès mažai tirtos, informacijos apie tai nèra, daugiau kalbèta apie rašybos tarmini pagrindą. Rašybą išsamiai aprašęs ir ịvertinęs Aleksas Girdenis daro išvadą, kad autorius vartojo to meto ịprastinị lenkų raidyną, jau XVIII a. gana vykusiai pritaikytą žemaičių tarmei [6]. Jono Palionio dèmesys daugiausia krypsta ị S. Stanevičių kaip apskritai ị kalbos normintoją [11, 160, 181].

Daukanto galūnių rašybos tyrimai apsiriboja tik pavieniais atvejais, dauguma jų morfologiniai, atskirai tikriniai vardai išskirti nebuvo. Abeciełoje esantis S. Daukanto rašmenų inventorius P. Joniko laikomas pagrindiniu, nes jis sudarytas remiantis lotyniškuoju raidynu [8, 179]. Jis pažymi, kad S. Daukanto noras skirtingai žymèti vienaskaitos kilmininko ir daugiskaitos vardininko galūnes $<\mathrm{a}>$ ir $<\hat{\mathrm{o}}>$ rašmenimis yra nusižiūrètas iš Mažosios Lietuvos raštų ir gramatikų (plačiau [8, 123, 180], dar žr. Biruté Vanagienė [14, 735-736]).

\section{TIKRINIŲ VARDŲ GALŪNIŲ ADAPTAVIMO TENDENCIJOS IR RAŠYBA SENUOSIUOSE RAŠTUOSE}

Senuosiuose raštuose, ypač bažnytinėse knygose esantys tikriniai vardai sudaro sunkumų nustatant, kurie vardai yra sulietuvinti, o kurie vartojami originalia forma [11,9]. Neretai tekstuose būdavo nesulietuvintų žodžių visiškai be galūnių, pvz., Reusneri. Apie svetimvardžių rašybos raidą daug rašè Vytautas Ambrazas [1], jos formavimuisi, dabarties situacijai aptarti yra skirtas ir Indrès Baltrušaitienès magistro darbas [2].

Tikrinių vardų ir kitų žodžių galūnių rašyba senuosiuose raštuose pasižymėjo tarminemis ypatybèmis. Pasirinkta pora rimtesnių gramatikų, parašytų iki XIX amžiaus. 
Štai Danieliaus Kleino gramatikoje Grammatica Lithvanica (1653), be ịprasto galūnių rašymo, išskiriami galūnių -as, -is sutraukimo ir iškritimo atvejai (kombinaciniai balsių kitimo būdai galūnèse). Sutraukimą D. Kleinas aiškina taip: „iš paskutinio vardų, neturinčių galūnès - as, -is, skiemens vidurinè raide dažniausia iškrinta, ir du skiemenys sutraukiami ị vieną“ $[9,429]$. Iškritusio „judriojo balsio“ grafinis žymėjimas pastebimas ir XVIII a. religiniuose raštuose bei giesmynuose [11,43]. Dalis tikrinių vardų pavyzdžių D. Kleino rašomi su lietuviškomis galūnèmis, dalis - be galūnių, jei tai nelinksniuojami svetimos kilmès pavadinimai, pvz.: Sion Sionas, Ifrael Izraelis.

Kristupo Sapūno ir Teofilio Šulco gramatika Compendium... buvo praktinio pobūdžio. Norminimo polinkius čia rodo tinkamiausios tarmès pasirinkimas [12, 15]. Knygoje rašoma, kad adaptuojant lietuvių kalbai tikrinius vardus, su jais vyksta ịvairių reiškinių. Paskutinè galūnès balsè (daugiausia trumpoji $a$, $i$, rečiau $e$ ) dažniausia numetama dèl apostrofo. Kartais išmetamos net gretimos vienodos balsès. Be to, ne visuomet dèl apostrofo raide numetama, kur gali būti numetama, ir tik tada, kai malonesnis yra trumpesnis žodis arba kai tai reikalinga metrui $[12,75]$. Šioje knygoje dauguma pavyzdžių yra su lietuviškomis galūnėmis, pvz., Jonas Jonas 20, Jonuttis Jonutis 20, kai kuriuose balsè iškritusi, pvz.: Jokubs Jokūbas 5.

Taigi galima išryškinti senųjų raštų galūnių rašybos tendenciją, kai adaptuojant tikrinius vardus galūnè rašoma nesutrumpinta, sutrumpinta ar visai nepridedama.

\section{TIKRINIŲ VARDŲ GALŪNIŲ ADAPTACIJA IR RAŠYBA S. STANEVIČIAUS IR S. DAUKANTO VERTIME}

S. Stanevičiaus ir S. Daukanto vertimų lietuviškumas, pritaikymas skaitytojui yra neatsiejamas nuo galūnių, ịvairių fonetinių procesų jose. Dažniausia tai tarminiai dalykai.

Remiantis turima medžiaga, galima išskirti kelias S. Stanevičiaus ir S. Daukanto (1) biblinių vardų galūnių rašymo grupes. Reikia pažymèti, kad neretai galūnė yra aukštaitiška - balsis neišmetamas, nes dažnai susidarytų nepatogus tarti priebalsių derinys, tačiau pasitaiko ir nepastovių atvejų, kai vienur galūnès išlaikomos sveikos, o kitur tokios pat galūnès balsis išmetamas (pvz.: Roboamas Roboamas (35) ir Ierobaams Jeroboamas (19)).

(1) S. Daukantas laikèsi tų pačių principų tiek lietuvindamas biblinius vardus, trumpindamas juos, tiek ir versdamas bendrinius žodžius. Jų a) jų netrumpino: abażas abažas (7), aicziojemas aičiojimas (30), krasztas $\sim$ kraštas (23), paikas $\sim$ paikas (31), paoiumas $\sim$ pavojumas (29), ublas $\sim$ ūblas (17), żombas $\sim$ žambas (28) ir t. t.; b) trumpino: 1) be apostrofo: aiczioiems $\sim$ aičiojimas (18), amars amaras (24), ludiejs liudejas (39), mediejs $\sim$ medèjas (40), nokieis $\sim$ nokejjis 'varžovas' (3), paskaninims $\sim$ paskaninimas (32), paskouijs $\sim$ paskuojis (16), prots $\sim$ protas (24), ragintois $\sim$ ragintojis (30), tîkiejems $\sim$ tikejjimas (17), tuszts $\sim$ tuščias (19), ums ūmas (17), undou $\sim$ vanduo (4), wieszpats viešpats (13) ir kt., 2) su apostrofu: aklum's aklumas (37), Aniol's aniolas 'angelas' (4), apmaud's apmaudas (18), apsikabinim's apsikabinimas (4), atmon's atmonas (41), erżel's eržilas (15), kaikar's $\sim$ kaikaras (35), rag's $\sim$ ragas $(10)$, raudon's $\sim$ raudonas (35), szimtinik's šimtinykas 'šimto karių viršininkas' (7), tarim's tarimas (9), tir's tyras (23), ukinik's ūkininkas (7), zwîlgteriejem's žvilgterejjimas (5) ir kt.; c) numetė visą skiemenị: daiktavardžiai: artos $\sim$ artojas (3), garbintos $\sim$ garbintojas (10), gelbietos $\sim$ gelbètojas (2), kepies $\sim$ kepejjas (30), padietos $\sim$ padètojas (2), rieditos $\sim$ rèdytojas (25), wainotos $\sim$ vainotojas (10), wasaros $\sim$ vasarojas (23), wies vejas (40), veiksmažodis: nebgiŏ nebgyvuoja 'nebegyvuoja' (38). 
Nesutrumpintos galūnès (2) vartotos dažniausia. Keletas pavyzdžių iš S. Stanevičiaus darbų (14x), pvz.: Darijušas Darijus, Saulis Saulius, Joramas Joramas, Samuelis Samuelis, Helis Helis, Asweras Ašeras, Galyjotas Galijotas, Giedeonas Gedeonas, Judas $\sim$ Judas, Labonas $\sim$ Labonas, Pompejuszas $\sim$ Pompejjas, Rafolas $\sim$ Rapolas, Symanas $\sim$ Simonas, Uryjoszius Ūrijas. Asmenvardžių galūnès S. Daukanto rašomos taip (20x), pvz.: Ablus Abelis (1), Amazias Amasajas (4), Antiokas Antiochas (4), Asswerus Ašeras (5), Cyrus Kiras (11), Danielùs Danielius (11), Darius $\sim$ Darius (11), Ezaus Ezavas (15), Ezekias Ezekijas (16), Iokbus Jokūbas (19), Ionatas Jonatanas (22), Iudoszus Judas (22), Mardokeus Mardochajas (24), Matatias Matatijas (24), Nabuchodozoras Nabuchodonosaras (26), Pompeius Pompejus (30), Roboamas Roboamas (35), Rubenas $\sim$ Rubenas (35), Tabiioszùs Tobijas (39), Urijoszius Ūrijas (42). Balsinès vyriškosios giminès galūnès rašomos tarmiškai (2x), pvz.: Aleksendra Aleksandras (3) (3), Aza Azazas (5). Šiuo atveju S. Daukantas pateikia tarminę vardo formą, plg. Žywate yra Alexandra Aleksandras (53).

Tokia galūnių vartosena, priešingai nei seniau rašiusių autorių, nèra paremta jų gimtąja, šiuo atveju - žemaičių, tarme, ji labiau buvo taikoma aukštaičiams. Daukanto dažnai vartojamų diakritikų bendrinių žodžių galūnèse pasitaiko ir čia, nors sistemingai jie nevartojami (2x), pvz.: Danielùs Danielius, Tabiioszùs Tobijas.

Rašydamas moteriškus vardus Daukantas laikosi lietuviškų galūnių sistemos (3x), pvz.: Fstera $\sim$ Estera (15), Rebeka Rebeka (33), Sara Sara (35), taip yra ir Stanevičiaus vertime (4x), pvz.: Iwa Ieva, Saba Seba, Estera Estera, Rebeka Rebeka.

Tikrinių vardų grupei priklauso ir bibliniai vietovardžiai, rašomi su visa galūne $(6 \mathrm{x})$, pvz.: Babilonije Babilonas (6), Egiptas Egiptas (3), Kananeje $\sim$ Kanaanas (7), Mezopotanîje $\sim$ Mesopotamija (24), Sirije Sirija (38), Tigrys $\sim$ Tigras (39), panašiai rašyta ir Stanevičiaus (3x) - Mezopotamija Mesopotamija, Niniwa Ninevé, Nilus $\sim$ Nilas.

Pasitaiko galūnių trumpinimo atvejų. Šiais išvardytais atvejais išryškejja žemaitiškas galūnių trumpinimas - balsių sutraukimas (kontrakcija). Daukantas jas rašo ir be apostrofo (5x): Abroms Abraomas (1), Gedeons Gedeonas (18), Ierobaams Jeroboamas (19), Samsons Samsonas (35), ir su apostrofu (11x): Absalon's Abšalomas (1), Adom's Adomas (2), Aman's Amanas (4), Amon's Amonas (4), Benjamîn's Benjaminas (6), Dowid's Dovydas (11), Iapet's Jafetas (19), Kain's Kainas (6), Kam's Chamas (7), Putipar's Potifaras (33), Sem's Semas (36). Abiem atvejais dažniausia trumpinamos galūnès - as su kamiengalio sonantais $m, n, r$, rečiau su sprogstamaisiais priebalsiais $t$ ir $d$.

Vardai rašomi ir be galūnès (12x), pvz.: Batuel Betuelis (6), Eliezer Eliezeras (14), Efraim $\sim$ Efraimas (15), Iabes Jabešas (19), Ieriko Jerichas (19), Manases $\sim$ Manasas (24), Moses Mozė (25), Noe Nojus (26), Raguel Raguelis (33), Saul Saulius (35), Semei Semas (36), Rakel Rachelè (33). Atkuriant dažniausia galūnè būtų -is, kitais atvejais -us, -as. Kodèl Daukantas šiuo atveju tiesiog neatkuria galūnių, galima tik numanyti - gal dèl

(2) Siekiant patikslinti galūnių rašybą, buvo atliktas nedidelis galūnių sudėtinių rašmenų tyrimas. Tirti sudètiniai rašmenys <à>, <è>, <é>, <á>, jų vartosenos atvejai Stanevičiaus darbe. Reikšmės lygintos su Daukanto darbų pavyzdžiais ir žiūrèta, kiek tai turejjo įtakos norminimui. Nustatyta, kad sudètiniai rašmenys Stanevičiaus darbe vartojami dėsningai tam tikrose pozicijose: vartojami labiau šaknyje, o galūnejje jie žymi tik daugiskaitos kilmininką, pvz., jawù javų, nu szesziù deszimtù nu šešių dešimtų 'nuo šešių dešimčių, jù jų. Užfiksuotas pavienis vienbalsinimo atvejis wandù vanduo. Šaknyje rašmenys su diakritikais vartojami ir po vieną, ir esantys dvigarsių sudètyje. Sudètinių rašmenų nèra daug, nes ir pats leidinukas nedidelis.

(3) Stanevičius pateikia vyriškąą formą Aleksandras. 
reto vardų paplitimo Lietuvoje, įvairiuose religiniuose raštuose. Jų rasta ir Stanevičiaus vertime (4x): Hely $\sim$ Helis, Noe $\sim$ Nojus, Roges $\sim$ Rogha, Rachel $\sim$ Rachelè.

Pasitaikė pavyzdžių, kai Daukantas nurodo tik lotynišką vardo variantą, pvz.: [Achabus] ward's Achabus, bi, $m \sim$ Ahabas 2; [Labanus] ward's Labanus, $i, m \sim$ Labanas 22.

Vietovardžių galūnès beveik netrumpinamos $(2 \mathrm{x})$, tik vietovardžio Harans $\sim$ Haranas (19), o vietovardžio Ieriko Jerichas (19) (lot. Iericho) išlaikoma originali galūnès forma, jų daugiau Stanevičiaus vertime (5x), pvz.: Chanaan Kanaanas, Gielboe Gilboja, Haran Haranas, Jerycho $\sim$ Jerichas, Sinai Sinajus.

Apibendrinant ši poskyrị reikia pasakyti, kad šiam negausiam leksikos sluoksniui būdinga gana tvarkinga galūnių rašybos ir adaptavimo sistema. Asmenvardžių galūnių Stanevičius praktiškai netrumpina - nerašo apostrofų, neišmeta balsių, tačiau jo vertime pasitaiko neadaptuotų tikrinių vardų - visiškai be galūnių. Daukanto tikrinių vardų galūnių lietuviškumas šiuo atveju kitoks - jos dažniau trumpinamos žymint apostrofais arba tiesiog nerašant raidès. Taigi šios galūnès yra daugiau žemaitiškos. Iš tiesų, Daukantas dažniausia lietuvino biblinius vardus, stengdamasis pateikti skaitytojui kuo grynesnę kalbą, adaptuodamas juos ir išlaikydamas aukštaitiškas galūnes.

\section{IŠVADOS}

1. Remiantis tyrimu nustatyta tokia tikrinių vardų galūnių adaptacija Daukanto ir Stanevičiaus darbuose: adaptuojant išlaikomi pridedamų galūnių balsiai, adaptuojant išmetami pridedamų galūnių balsiai arba vardai visiškai neadaptuojami (nepridedama lietuviška galūnè).

2. Stanevičius tikrinių vardų galūnes rašè aukštaitiškai, Daukantas kaip etalono laikėsi savo žemaičių tarmès fonetinių ypatybių.

3. Lyginant Stanevičiaus ir Daukanto tikrinių vardų rašybą, Stanevičius labiau išlaikè galūnes, Daukantas dažniau vartojo žemaitiškas galūnes, jo tarminès ypatybès - galūnių trumpejjimas - ryškesnès.

4. Pastebėta tendencija: jei tikrinis asmenvardis ar vietovardis buvo mažiau pažistamas autoriui, jis buvo rašomas be galūnès (neadaptuojamas), jo šaknis palikta tokia, kokia yra originalo tekste.

5. Daukanto ir Stanevičiaus tikrinių vardų adaptacija ir galūnių rašymas nesiskiria nuo senųjų autorių gramatikų principų.

Gauta 20150427

Priimta 20160331

\section{Literatūra ir šaltiniai}

[1] AMBRAZAS, Vytautas. Svetimu tikrinių vardų rašymas. Vilnius: Lietuvių kalbos institutas, 2008 .

[2] BALTRUŠAITIENĖ, Indrè. Svetimvardžiu rašymo tradicijos formavimasis Lietuvoje. Magistro darbas (rankraštis). Vilnius: Vilniaus universitetas, 2009.

[3] [Daukantas, Simonas.] [Antraščų vertimas.] C[harles] F[rançois] L'homond. Epitome Historiae Sacrae. Petropilie. LMAB RSS, L-19/146, 1838.

[4] [Daukantas, Simonas.] Zodrodys. Charles François L'Homond, Epitome Historiae Sacrae. Petropilie, 1-42. LMAB RSS, L-19/146, 1838.

[5] DAUKANTAS, Simonas. Abecięla lîjtuwiû-kalnienû ir źiamajtiû kałbos. Petropilis: K. Krajaus spaustuve, 1842. 
[6] GIRDENIS, Aleksas. Simono Stanevičiaus rašyba ir jo tarmès fonologinè sistema. Kalbotyros darbai. III. Vilnius, 2001.

[7] GUDELIENĖ, Birutè. Biblinių vardų norminimo problemos Simono Daukanto ir Simono Stanevičiaus Epitome Historiae Sacrae vertime ir dabar. Pranešimas 21-oje tarptautinèje Jono Jablonskio konferencijoje „Šiuolaikinès kalbos tyrimai ir problemos“. Vilniaus universitetas, Lietuvių kalbos institutas, 2014 m. Spalio 3 d., p. 13-15. Prieiga per internetą: http://www.flf.vu.lt/struktura/ katedros/lietuviu-kalbos-katedra\#naujienos

[8] JONIKAS, Petras. Lietuviu bendrinès kalbos kūrimasis antrojoje XIX amžiaus pusèje. Čikaga: Pedagoginis literatūros institutas, 1972.

[9] KLEINAS, Danielius. Pirmoji lietuviu kalbos gramatika, 1653 metai. Vilnius: Valstybinè politinès ir mokslinès literatūros 1-kla, 1957.

[10] MACIEJAUSKIENĖ, Vitalija. Lietuviu pavardžiu susidarymas XIII-XVIII a. Vilnius: Mokslas, 1991.

[11] PALIONIS, Jonas. Lietuvių literatūrinè kalba XVI-XVII a. Vilnius: Mintis, 1967.

[12] STUNDŽIA, Bonifacas; EIGMINAS, Kazimieras (par.). Compendium grammaticae Lithvanicae. Sapūno ir Šulco gramatika. Vilnius: Mokslo ir enciklopedijų leidybos institutas, 1997.

[13] Nutarimas „Dèl Biblijos vardų adaptavimo principų“. Valstybès žinios, 1997 rugs. 12, Nr. 842122, p. 60-61.

[14] VANAGIENĖ, Birutė; MERKYS, Vytautas (sud.). Redakcinės pastabos. Simonas Daukantas. Raštai. T. I. Vilnius: Vaga, 1976, p. 735-742.

\section{Endings of proper names in Simonas Daukantas' and Simonas Stanevičius' translations of Epitome Historiae Sacrae}

Summary

The relevance of the article lies in the analysis of standardising biblical proper names and their comparison because there have been no well-established orthography of the biblical proper names and a thorough analysis of proper names used in the old works.

The article attempts to examine morphological issues in Stanevičius' and Daukantas' sources, with a special focus on the Lithuanianness of the endings of translated proper biblical names. The article tries to establish the nature of standardisation applied by each author, the influence of the dialect on the spelling of endings, and the relation of orthography of endings used by both translators. It has established that some of the characters with diacritics used by Daukantas mark the endings of certain cases. Simonas Stanevičius uses characters with diacritics in an extensive volume of his works, however, they denoted the place of the stress; therefore the use of Daukantas' works for morphological studies was only too reasonable.

Adaptation of names was discussed as early as in the grammar of Daniel Klein Grammatica Lithvanica (1653). Klein specifies the cases of contraction and omitting of endings -as, -is (combined methods of vowel change in the endings). 
The standardised adaptation of biblical names in Lithuanian appeared only in the Dictionary of Biblical Names (Biblijos vardu žodynas, 2002) published as late as in 2000. It names numerous principles, and the paramount ones are as follows: 1. According to the international practice of translating the Bible into modern languages, the translation of the Old Testament names should be as close to the Hebrew (Aramaic) original as possible if their Lithuanian forms have a short history of use. Other names that fell into the Lithuanian language through the Greek (Septuagìnta) and Latin (Vulgatà) translations of the Old Testament rather than directly from the Hebrew or through the New Testament and that have a well-established form should be treated as traditional ones. 2 . The rest of the principles are associated with phonetic issues and adaptation based on adding Lithuanian endings or ends of the word or syllabus.

Stanevičius does not practically shorten the endings of the names - he does not use apostrophes and does not omit vowels though his translations appear to include proper names with no endings at all.

Lithuanianness of the endings of proper names translated by Daukantas is different. There are considerably more cases of shortening the endings of proper names expressed by way of apostrophes or simply omitting a letter. These endings are closer to Samogitian, therefore, they imply syncope. To sum it up, Daukantas most often lithuanianised biblical names in order to provide the reader with as much pure language as possible.

Keywords: Daukantas, Stanevičius, biblical names, standardisation, spelling of the endings 